\title{
Resistência de Genótipos de Soja à Phakopsora Pachyrhizi
}

\author{
Luís Antônio Siqueira de Azevedo ${ }^{1}$, Fernando Cezar Juliatti², Modesto Barreto ${ }^{3}$
}

\begin{abstract}
${ }^{1}$ Professor Adjunto Doutor do Instituto de Biologia,Departamento de Entomologia e Fitopatologia,Universidade Federal Rural do Rio de Janeiro - Câmpus Seropédica - luisasa@ufrrj.br; ${ }^{2}$ Professor Titular do Instituto de Ciências Agrárias, Universidade Federal de Uberlândia - Câmpus Umuarama - juliatti@ufu.br; ${ }^{3}$ Professor Assistente Doutor do Departamento de Fitossanidade, FCAV/UNESP - Câmpus de Jaboticabal modesto@fcav.unesp.br

Autor para correspondência: Luís Antônio Siqueira de Azevedo

Data de chegada: 29/06/2005. Aceito para publicação em: 24/10/2006.
\end{abstract}

\section{RESUMO}

Azevedo, L.A.S.; Juliatti, F.C.; Barreto, M.. Resistência de Genótipos de Soja à Phakopsora pachyrhizi. Summa phytopathologica, v.33, n.3, p.252-257, 2007.

O presente trabalho teve como objetivo, quantificar a resistência à Phakopsora pachyrhizi em 50 genótipos de soja na região do cerrado. Foi conduzido em Uberlândia, MG, um experimento em casa de vegetação, durante o período de janeiro a julho de 2004. Foram avaliados os seguintes parâmetros de resistência: período latente médio, número médio de pústulas por $\mathrm{cm}^{2}$ e severidade da ferrugem. Com base nesses parâmetros, calculou-se a área abaixo da curva de progresso da doença. Após, análise de variância e teste de médias que foram comparadas pelo teste de Duncan ao nível de $5 \%$ de probabilidade, utilizando-se o software ESTAT. Foram encontradas diferenças significativas entre os genótipos de soja para os parâmetros estudados. As cultivares Emgopa 313 e Monsoy 8211 apresentaram menor período latente médio, menor número de pústulas, severidade e área abaixo da curva do progresso da doença, sendo classificadas como resistentes ao patógeno no experimento realizado.

Palavras-chave adicionais: Phakopsora pachyrhizi, Glycine max, genótipo, epidemiologia.

\section{ABSTRACT}

Azevedo, L.A.S.; Juliatti, F.C.; Barreto, M.. Resistance of Soybean Genotipes of the Cerrado Region to Rust Caused by Phakopsora pachyrhizi. Summa phytopathologica, v.33, n.3, p.252-257, 2007.

The aim of the present study, was to quantify the resistance in fifty soybean genotipes of the cerrado region to the rust caused by Phakopsora pachyrhizi .One experiment in greenhouse were conducted in Uberlândia, MG from January to July 2004. Average latent period, number of pustules per $\mathrm{cm}^{2}$ and disease severity were evaluated.
Based on these parameters, it was calculated the area under the disease progress curve. Significant differences were found among the soybean genotipes to the three studied parameters. The cultivars Emgopa 313 and Monsoy 8211 were more resistant to Pkakopsora pachyrhizi in greenhouse experiment.

Additional Keywords: Phakopsora pachyrhizi, Glycine max, genotype, epidemiology.

A ferrugem asiática da soja (Phakopsora pachyrhizi H. Sydow \& Sydow), (FAS) até a safra 2004/05, já havia sido relatada na Austrália, Rússia, Coréia, Japão, China, Taiwan, Filipinas, Nepal, Índia, Nigeria, Moçambique, Ruanda, Uganda, África do Sul, Zâmbia, Zimbábue, Paraguai, Brasil e Argentina. No Brasil, a FAS já foi identificada em todos os Estados produtores. O dano, devido à incidência da FAS tem variado desde $10 \%$ a 91\%. Na safra 2005/2006, o nível epidêmico que a doença atingiu em diversas regiões produtoras do Brasil, acarretou perdas estimadas em US\$ 5 bilhões. Sempre que o processo de infecção inicia-se a partir do estádio R1/R2 da soja, é observado aumento significativo do dano, embora a ocorrência da doença em estádios fenológicos mais avançados, também possa acarretar dano muito elevado $(1,3,24)$.

Os sintomas da ferrugem asiática podem surgir em qualquer momento do ciclo fenológico da cultura, porém tem surgido de forma mais freqüente em plantas próximas ou em plena floração. Os sintomas são observados mais freqüentemente nas folhas baixeiras, com lesões de cor amarela que se transformam em manchas de forma poligonal ou arredondada de coloração bronzeada a marrom. Um detalhe importante para a diagnose precisa da doença é a formação abundante de urédias apenas na face inferior das folhas. Estas ocorrem em forma de bolhas esbranquiçadas e brilhantes que explodem rapidamente, liberando grande quantidade de urediniósporos semelhantes a grãos de açúcar cristal. (1,3).

Pesquisas realizadas a partir da década de setenta $(4,7,17,18,19$, 22) na área de obtenção de cultivares de cereais resistentes aos agentes causais da ferrugem e da brusone do arroz demonstram o fenômeno, que tem sido denominado como ferrugem lenta ("slow rusting"). A ferrugem lenta é considerada como uma forma de resistência parcial. Esta resistência tem como característica a redução da taxa de epidemia através da diminuição do número e tamanho das lesões, diminuição da produção de urediniósporos e do aumento do período latente de infecção. Isso faz com que a população do patógeno seja reduzida, diminuindo a quantidade de inóculo e, conseqüentemente, a doença. A 
taxa de infecção aparente (r) é também reduzida no campo.

No patossistema soja P.pachyrhizi, há relatos da existência de quatro genes dominantes controlando a resistência, denominados Rpp1 a Rpp4. Os genes foram identificados em introduções de plantas e cultivares $(6,12)$. A resistência parcial ou a resistência que reduz a taxa de infecção, foi também relatada para a FAS onde linhagens com resistência parcial em avaliações de campo foram classificadas como moderamente resistentes, uma vez que poucas lesões se desenvolveram durante o ciclo da cultura (21). De acordo com Hartman (13) e Wang \& Hartman (21), a identificação e a utilização da resistência parcial, em programas de melhoramento de soja, têm sido limitadas. Os métodos de avaliação consomem tempo e dificultam a incorporação em programas de melhoramento .

A FAS é uma doença recente no Brasil, foi constatada em 2001 na cidade de Londrina - PR e poucas cultivares apresentam resistência. A seleção de cultivares resistentes começou no inverno de 2001, na Embrapa Soja, em Londrina - PR. Nos testes em condições controladas realizados em casa de vegetação, foram identificadas cultivares com resistência ao patógeno, baseado na presença de lesões de hipersensibilidade do tipo RB ("Reddish Brown"). As cultivares BRS 134, BRMS Bacuri, CS 201 (Esplendor), FT 2, FT 17, FT 2001, IAC PL-1, KIS 601 e Ocepar 7, quando inoculadas com urediniósporos de P. pachyrhizi, apresentaram reação de hipersensibilidade, produzindo lesões RB com pouca ou nenhuma esporulação. Com base na genealogia desse grupo de cultivares, verificou-se que a resistência era derivada da cultivar FT-2 e controlada por um gene dominante $(11,23)$.

No Brasil, em função da introdução recente do patógeno, um estudo completo de raças ainda não foi realizado. Segundo Godoy \& Arias (11), algumas informações já estão disponíveis baseadas nas reações das cultivares observadas desde a safra 2000|2001. Isolados do fungo provenientes de regiões do Mato Grosso (Sorriso e Lucas do Rio Verde) foram utilizados em inoculações em casa de vegetação, em junho de 2003. Esse isolado foi capaz de vencer a resistência da cultivar FT-2 e conseqüentemente, de todas as demais cultivares identificadas em 2001 como resistentes, sendo caracterizada, portanto, como uma nova raça do fungo. As cultivares que inicialmente produziram somente lesões tipo RB, quando inoculadas com urediniósporos do isolado do Mato Grosso, passaram a se comportar como cultivares suscetíveis, produzindo lesão do tipo castanho-clara, com abundante esporulação.

A alta severidade da ferrugem no cerrado observada na safra de 2003/2004 e o fato das cultivares resistentes em 2001/2002 serem suscetíveis aos isolados de P. pachyrhizi do cerrado, é uma forte evidência da plasticidade genética do fungo $(14,24)$. Devido à variabilidade do patógeno, principalmente no cerrado brasileiro, estudos para identificação de cultivares resistentes devem ser realizados, principalmente de cultivares comerciais que apresentem resistência parcial. Este tipo de resistência é muito mais estável e durável para patógenos que apresentam alta variabilidade como é o caso de Phakopsora pachyrhizi.

O objetivo deste trabalho foi de quantificar a resistência à Phakopsora pachyrhizi em 50 genótipos de soja na região do cerrado.

\section{MATERIAL E MÉTODOS}

Para a avaliação da resistência dos genótipos à FAS, foi conduzido em Uberlândia, na Fazenda Capim Branco da Universidade Federal de Uberlândia, um experimento em casa de vegetação, no período de janeiro a julho de 2004. Foram semeadas em vasos plásticos com capacidade para 2,0 kg de solo, sementes de 50 genótipos de soja (Tabela1). Foi utilizado o delineamento experimental inteiramente casualizado, com cinco repetições e duas plantas por repetição. Foram avaliados os seguintes parâmetros de resistência parcial: período latente médio, número médio de pústulas por folíolo e severidade das cultivares à ferrugem asiática segundo escala diagramática de Juliatti \& Polizel (15) (Figura 1).

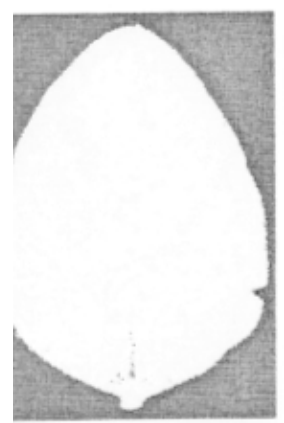

$0 \%$

$51-75 \%$

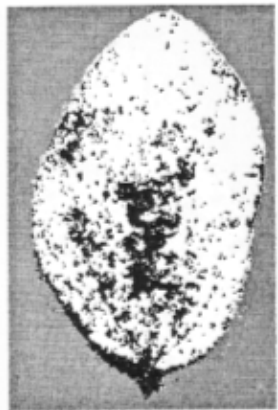

$1-25 \%$

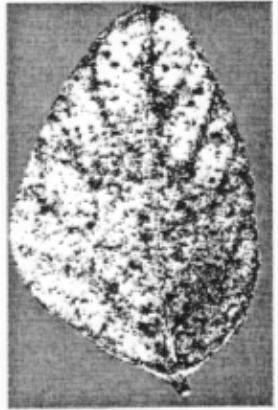

$26-50 \%$

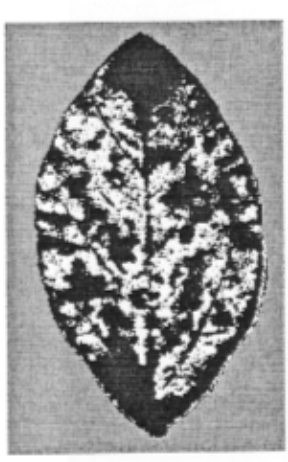

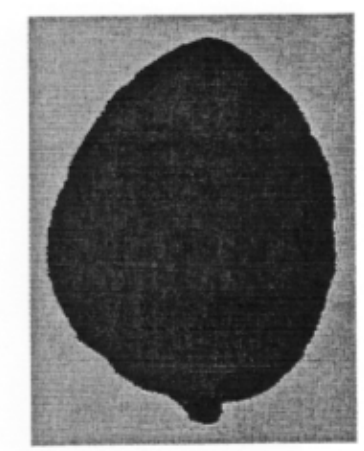

$76-100 \%$
Figura 1.Escala diagramática utilizada para avaliar a severidade da Ferrugem Asiática da Soja em porcentagem de área foliar infectada.

Para a avaliação dos parâmetros monocíclicos citados, plantas de soja dos 50 genótipos, foram inoculadas no estádio do segundo trifólio expandido (V 3), com uma suspensão ajustada para $2 \times 10^{5}$ urediniósporos/ml, com aproximadamente $90 \%$ de germinação, dispersos em água destilada com Tween, na dosagem de $0,5 \%$. Foi utilizado um pulverizador manual com capacidade para 1,0 litro. Os urediniósporos usados como inóculo, foram obtidos por meio de isolamento monopustular e multiplicados na cultivar de soja suscetível a FAS Conquista.

Após a inoculação as plantas permaneceram em casa de vegetação com temperatura de $25 \pm 3^{\circ} \mathrm{C}$, com turnos de molhamento por aspersão de 15 minutos a cada 2 horas. As avaliações foram realizadas através da contagem do número de pústulas por centímetro quadrado (no. pústulas $\mid \mathrm{cm} 2$ ), realizadas no folíolo central do primeiro trifólio e em toda a planta. As avaliações foram realizadas aos seis dias após a inoculação. Foram realizadas 5 avaliações guardando o intervalo de 3 dias cada uma. A severidade da FAS foi quantificada também no folíolo central com o auxílio de uma escala diagramática (Figura 1), pela avaliação visual da porcentagem de área foliar infectada. Para calcular o período latente médio (PLM), transformou-se o número de pústulas presentes a cada três dias em proporção do número total de pústulas, com o emprego da equação de Shaner \& Hess (20) : 
$\mathrm{PLM}=\Sigma$ Pi Ti onde,

$\mathrm{Pi}$ = proporção de pústulas novas surgidas na i - ésima observação, em relação ao número final de pústulas na $\mathrm{n}$ - ésima observação;

$\mathrm{Ti}=$ número de dias decorridos desde a inoculação até a i-ésima observação

$\mathrm{n}=$ número total de observações

Com base também nessas variáveis, foi calculada a área abaixo da curva de progresso da doença.

AUDPC $==\Sigma\left[\left(\mathrm{Y}_{\mathrm{i}+1}+\mathrm{Y}_{\mathrm{i}}\right) / 2\right]\left[\mathrm{X}_{\mathrm{i}+1}-\mathrm{X}_{\mathrm{i}}\right]$ onde,

$\mathrm{Y}_{\mathrm{i}}=$ média de doença ( por unidade de tempo) na $\mathrm{i}$ - ésima observação ;

$\mathrm{X}_{\mathrm{i}}=$ tempo em (dias) na i - ésima observação e,

$\mathrm{n}=$ número total de observações

Foi realizada a análise de variância e as médias foram comparadas pelo teste de Duncan, ao nível de 5\% de probabilidade, utilizando-se o software ESTAT.

\section{RESULTADOS E DISCUSSÃO}

\section{Período latente médio}

A média do período latente médio dos genótpos variou de 11,70 a 15,97 dias (Tabela 1). Houve diferenças significativas entre as médias dos genótipos. Neste ensaio três cultivares apresentaram período latente mais longo: Coodetec 208, IAC 25 e Monarca. Essas cultivares apresentaram um período latente maior que 15 dias. De acordo com Ribeiro do Vale (22) e Balardin (2), cultivares com período latente superior a 15 dias possuem resistência parcial. Os resultados obtidos nesse ensaio, permitem afirmar que essas cultivares comportaram-se como medianamente resistentes à ferrugem da soja. As cultivares Fortuna, Pétala e Monsoy 8222, comportaram-se como mais suscetíveis à ferrugem, apresentando período latente médio menor.

Em estudos em casa de vegetação, com a ferrugem da soja, Marchetti et al. (16) e Bromfield et al. (5), observaram que as combinações patógeno-hospedeiro que resultaram em reações tipo $\mathrm{RB}$, apresentaram períodos latentes mais longos, taxas de aumento do número de pústulas reduzido e lesões menores quando comparadas com interações suscetíveis que resultaram em reações tipo TAN.

\section{Número de pústulas por $\mathrm{cm}^{2}$}

A média do número de pústulas por $\mathrm{cm}^{2}$ variou de 4,54 a 7,88 (Tabela 1). Houve diferenças significativas entre as médias dos genótipos. Neste ensaio, três genótipos apresentaram significativamente um menor número de pústulas por $\mathrm{cm}^{2}$ : Emgopa 313, Nambu e Monsoy 8211. Os resultados obtidos nesse ensaio, permitem afirmar que esses genótipos comportaram-se como mais

Tabela 1. Genótipos de soja, período latente médio em dias e número médio de pústulas por $\mathrm{cm}^{2}$ de Pakopsora pachyrhizi em condições de casa de vegetação.

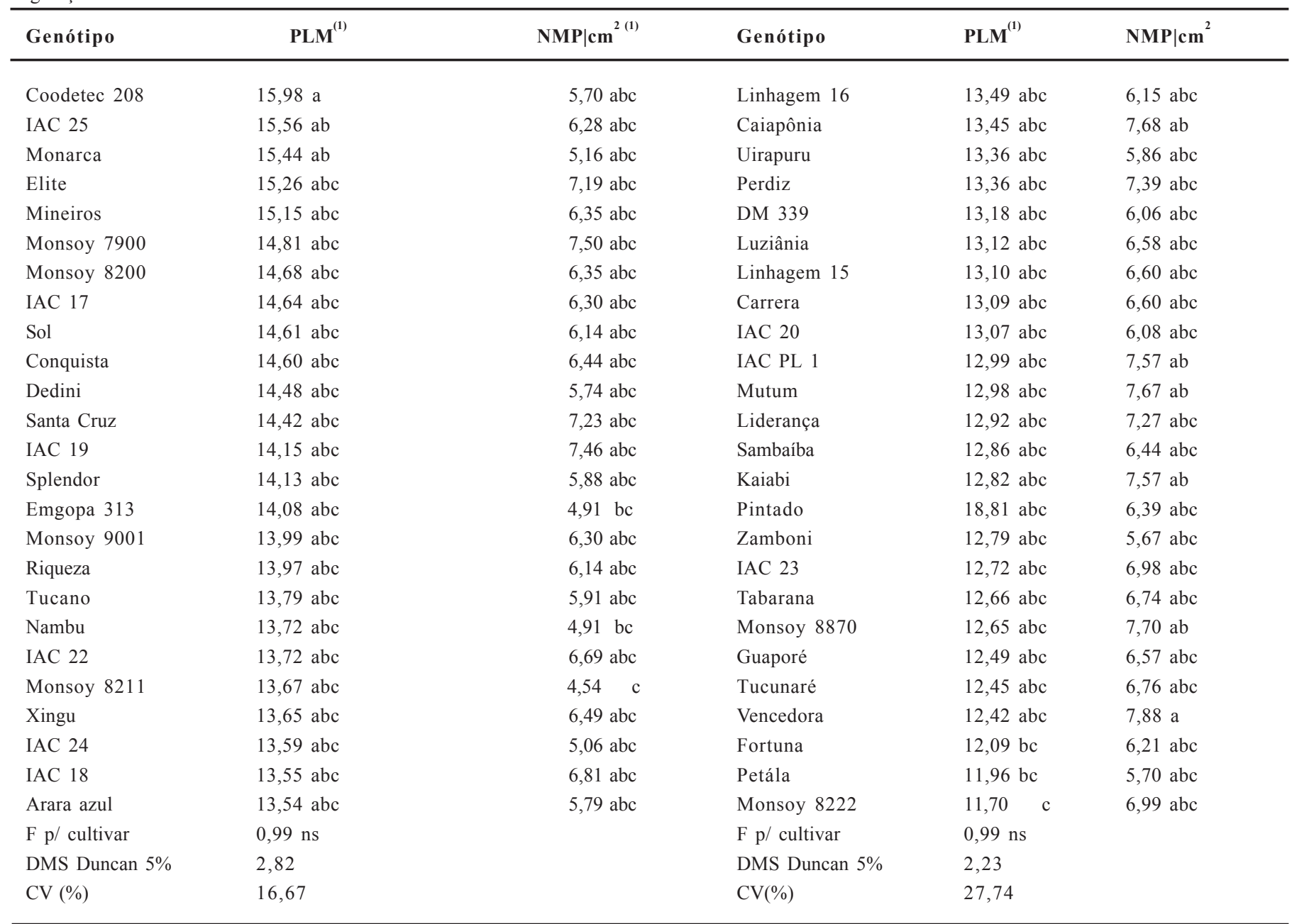

${ }^{1}$ As médias seguidas da mesma letra não diferem entre si, ao nível de 5\%, pelo teste de Duncan. Cada repetição é média de 10 plantas. 
resistentes à ferrugem da soja, porque produziram um menor número de pústulas por $\mathrm{cm}^{2}$. Por outro lado, as cultivares Vencendora, Monsoy 8870, Caiapônia, Mutum, Kaiabi, IAC PL1 e Monsoy 7900 e IAC 19 apresentaram significativamente um número mais elevado de pústulas por folíolo; logo maior suscetibilidade ao patógeno.

A resistência parcial à ferrugem da soja foi estudada por Vale, Zambolim e Chaves (22) e poucas cultivares apresentam resistência. Em 2002, na Embrapa Soja, selecionaram-se cultivares que apresentaram baixa severidade de doença e| ou lesões tipo RB, significando resistência parcial. Yorinori (24) testou 432 genótipos de soja com isolados de P.pachyrhizi obtidos em 2002 (raça do Centro Sul) e observou que alguns se mostraram resistentes como :BRMS Bacuri, FT 2001, KIS 601, BRS 134, CS 201, FT 2, FT 3 e FT 17. Porém, todos esses genótipos apresentaram-se como suscetíveis em 2003.

\section{Severidade (\% de área foliar infectada)}

A média da severidade da FAS nos genótipos em casa de vegetação variou de 7,48 a 10,02\% de área foliar afetada (Tabela 2 ). Houve diferenças significativas entre as médias dos cultivares. Neste ensaio, três cultivares apresentaram uma severidade menor à ferrugem: Monsoy 8211, Fortuna e Emgopa 313.

Os resultados obtidos nesse ensaio, permitem afirmar que as cultivares, Monsoy 8211, Fortuna e Emgopa 313 apresentam resistência ao patógeno, porque tiveram uma menor severidade da doença. Contrariamente, as cultivares IAC PL1, Kaiabi, Linhagem 15, Monsoy 8870 e Pintado, comportaram-se como mais suscetíveis à P.pachyrhizi, porque apresentaram significativamente uma maior severidade da doença.

Costamilan et al. (8) observaram o comportamento em campo dos genótipos de soja BRMS Bacuri, BRS 60 Celeste, BRS 133, BRS 134,

Tabela 2.Severidade e área abaixo da curva do progresso (AACPD) da ferrugem asiática em 50 genótipos de soja em casa de vegetação.

\begin{tabular}{|c|c|c|c|c|c|}
\hline Genótipo & Severidade de $P$. pachyrhizi ${ }^{(1)}$ & $\mathrm{AACPD}^{(2)}$ & Genótipo & $\begin{array}{l}\text { Severidade } \\
\text { de } P \text {. pachyrhizi }\end{array}$ & AACPD \\
\hline IAC PL 1 & 10,02 a $*$ & 23,97 abcd & Caiapônia & 9,17 abcde & 23,47 abcd \\
\hline Kaiabi & 9,89 a & $27,23 \mathrm{a}$ & Elite & 9,17 abcde & 23,11 abcd \\
\hline Linhagem 15 & $9,76 \mathrm{ab}$ & 24,07 abcd & IAC 23 & 9,08 abcdef & 23,75 abcd \\
\hline Monsoy 8870 & $9,75 \mathrm{ab}$ & $24,52 \mathrm{abc}$ & Monsoy 8222 & 9,04 abcdef & 24,31 abcd \\
\hline Pintado & $9,75 \mathrm{ab}$ & $25,26 \mathrm{ab}$ & Conquista & 9,04 abcdef & 21,63 abcd \\
\hline Guaporé & $9,63 \mathrm{abc}$ & 24,33 abcd & Monsoy 9001 & 9,02 abcdef & $23,93 \mathrm{abcd}$ \\
\hline Monsoy 7900 & $9,62 \mathrm{abc}$ & $24,56 \mathrm{abc}$ & Mineiros & 8,98 abcdef & 24,00 abcd \\
\hline IAC 20 & 9,92 abc & $23,90 \mathrm{abcd}$ & Monsoy 8200 & 8,98 abcdef & 22,34 abcd \\
\hline Tucunaré & $9,60 \mathrm{abc}$ & $24,56 \mathrm{abc}$ & Sambaíba & 8,96 abcdef & 23,22 abcd \\
\hline Mutum & 9,50 abcd & $24,77 \mathrm{abc}$ & Nambu & 8,94 abcdef & 21,77 abcd \\
\hline Sol & $9,50 \mathrm{abcd}$ & $22,77 \mathrm{abcd}$ & Liderança & 8,91 abcdef & 23,35 abcd \\
\hline Pétala & 9,49 abcd & $24,55 \mathrm{abc}$ & Luziânia & 8,75 abcdef & 21,73 abcd \\
\hline Arara azul & 9,47 abcd & $24,85 \mathrm{ab}$ & Tabarana & 8,75 abcdef & 23,22 abcd \\
\hline IAC 22 & 9,47 abcd & $24,49 a b c$ & Uirapuru & 8,70 abcdef & 20,80 bcd \\
\hline Perdiz & 9,47 abcd & $24,55 \mathrm{abc}$ & IAC 24 & 8,65 abcdef & 21,64 abcd \\
\hline I AC 25 & 9,47 abcd & 23,09 abcd & DM 339 & 8,65 abcdef & 22,47 abcd \\
\hline Xingu & 9,44 abcde & 23,36 abcd & IAC 17 & 8,34 abcdef & 22,38 abcd \\
\hline Carrera & 9,37 abcde & 23,08 abcd & Splendor & 8,32 abcdef & $22,21 \mathrm{abcd}$ \\
\hline IAC 19 & 9,36 abcde & $25,12 \mathrm{ab}$ & Riqueza & 8,17 bcdef & 22,51 abcd \\
\hline Santa Cruz & 9,31 abcde & 23,71 abcd & Linhagem 16 & 8,13 bcdef & 21,93 abcd \\
\hline Vencedora & 9,31 abcde & $25,86 \mathrm{ab}$ & Coodetec 208 & $8,00 \quad$ cdef & 21,22 bcd \\
\hline Monarca & 9,21 abcde & 21,77 abcd & Dedini & 7,88 & 21,22 \\
\hline IAC 18 & 9,18 abcde & 23,84 abcd & Monsoy 8211 & 7,76 & 18,71 \\
\hline Tucano & 9,18 abcde & $22,61 \mathrm{abcd}$ & Fortuna & 7,75 & 21,25 \\
\hline Zamboni & 9,18 abcde & 23,69 abcd & Emgopa 313 & 7,48 & $19,09 \quad \mathrm{~cd}$ \\
\hline $\mathrm{F}$ p/ cultivar & $1,60 \mathrm{~ns}$ & & $\mathrm{~F} \mathrm{p/} \mathrm{cultivar}$ & $1,01 \mathrm{~ns}$ & \\
\hline DMS Duncan 5\% & 1,33 & & DMS Duncan 5\% & 4,45 & \\
\hline $\mathrm{CV}(\%)$ & 11,83 & & CV $(\%)$ & 15,42 & \\
\hline
\end{tabular}

${ }^{(1)}$ Médias seguidas da mesma letra não diferem estatiscamente entre si, pelo teste de Duncan a $5 \%$. Cada repetição é média de 10 plantas.

* \% de área foliar infectada.

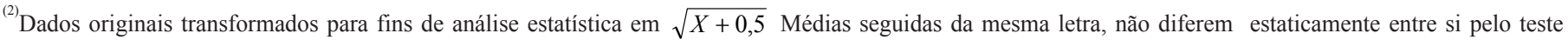
de Duncan a 5\%.Cada repetição é média de 10 plantas.

BRS 135, BRS 136, Campos Gerais, CS 201 (Esplendor), Embrapa 59, FT 2, FT 3, FT 17, FT 2001, IAC 3, IAC PL-1, KIS 601 e Ocepar 7 em condições naturais de infecção de ferrugem. De acordo com os autores, os melhores materiais, foram BRMS Bacuri, FT 2001, KIS 601, BRS 134, CS 201 (Esplendor), FT 2, FT 3 e FT 17. Não foi observada reação tipo RB. Na safra 2002/03, Godoy et al. (10) acompanharam o progresso da ferrugem em Londrina, PR, em 18 cultivares comerciais de soja, cultivadas, em duas épocas de semeadura (novembro e dezembro). A evolução da doença e a severidade da doença nas cultivares variaram em função da época de semeadura. Entre as cultivares testadas, BRS 134 foi a única que apresentou resistência à doença.

\section{Área abaixo da curva do progresso da doença (AACPD)}

A média dos valores da área abaixo da curva do progresso da doença (AACPD) nos folíolos variou de 18,71 a 27,23 (Tabela 2). Houve diferenças significativas entre as médias. As cultivares Emgopa 313 e Monsoy 8211 apresentam menores valores de AACPD. Os 
resultados obtidos nesse ensaio, permitem afirmar que essas cultivares comportaram-se como medianamente resistentes à P.pachyrhizi. Por outro lado, Os genótipos IAC PL1, Kaiabi, Vencedora, Pintado, IAC 19 e Arara Azul apresentaram valores significativamente mais elevados de AACPD, logo foram mais suscetíveis à FAS.

Cruvinel et al. (9) estudaram o progresso da ferrugem asiática em nove cultivares de soja de ciclo precoce, médio e tardio em Senador Canedo, GO e usaram a AACPD e a AACPD relativa (AACPD/ Número de dias da epidemia) encontrando diferenças, tanto entre as cultivares com o mesmo ciclo quanto entre as cultivares de ciclos diferentes. Trabalhos conduzidos por Balardin et al (2) para verificar a presença de resistência parcial em cultivares de soja à P.pachyrhizi, demonstraram variação na taxa de progresso da doença entre diferentes cultivares de soja. Os autores observaram variação de sensibilidade das mesmas em relação ao patógeno quando inoculadas em diferentes estádios fenológicos. De modo geral, as cultivares apresentaram menor sensibilidade ao patógeno quando inoculadas entre os estádios V4 e V5, sendo mais sensíveis à infecção nos estados V1 e R1.

\section{Correlação entre os parâmetros de resistência}

As mais altas correlações entre os parâmetros de resistência parcial foram observadas entre o número médio de pútulas por $\mathrm{cm}^{2}$ e área abaixo da curva do progresso da doença $(r=0,91 *)$, bem como entre o número médio de pústulas por $\mathrm{cm}^{2}$ e a severidade da doença. $(\mathrm{r}=$ $0,87 *$ ).Alta correlação foi também encontrada entre a área abaixo da curva de progresso da doença e a severidade $(r=0,89 *)$.Correlações muito baixas foram encontradas entre o período latente médio, o número médio de pústulas por $\mathrm{cm}^{2}$, a área sob a curva do progresso da doença e a severidade da doença (Tabela 3 ).

Tabela 3.Correlação entre os parâmetros de resistência em casa de vegetação.

\begin{tabular}{|c|c|c|c|}
\hline Parâmetros & $\mathrm{NMP} \mid \mathbf{c m} 2$ & AACPD & SEVERIDADE \\
\hline $\begin{array}{l}\text { PLM } \\
\text { NMP } \mid \mathrm{cm}^{2(2)} \\
\text { AACPD }^{(3)}\end{array}$ & 0,05 & $\begin{array}{l}0,13 \\
0,91 *\end{array}$ & $\begin{array}{l}0,06 \\
0,87 * \\
0,89 *\end{array}$ \\
\hline
\end{tabular}

(1) PLM - Período latente médio

${ }^{(2)} \mathrm{NMP} \mid \mathrm{cm}^{2}-$ Número médio de pústulas por $\mathrm{cm}^{2}$

(3) AACPD - Área sob a curva do progresso da doença

* - significativo a $1 \%$.

De acordo com os dados obtidos neste estudo, pode-se concluir que as cultivares Emgopa 313 e Monsoy 8211 apresentaram menor número médio de pústulas por $\mathrm{cm}^{2}$, menor severidade e valores menores da área abaixo da curva do progresso da doença; logo são resistentes à FAS. As cultivares Fortuna, Coodetec 208, IAC $25 \mathrm{e}$ Monarca foram moderadamente resistentes apenas quando se avaliou o período latente médio e severidade. As cultivares Emgopa 313 e Monsoy 8211 apresentaram maior nível de resistência, porque mostraram : menor número de pústulas por $\mathrm{cm}^{2}$, menores valores de severidade à ferrugem e de AACPD. Pode-se também concluir que todos os parâmetros de resistência estudados foram eficientes na detecção de diferenças na resistência entre os genótipos, tendo Emgopa 313 e Monsoy 8211 apresentado sempre os maiores níveis de resistência.

A identificação de cultivares comerciais com resistência parcial é a primeira etapa de um programa integrado de controle da ferrugem asiática. No futuro, essas cultivares poderão ser recomendadas para determinadas regiões e, dessa forma, reduzir a dependência de aplicações de fungicidas.

\section{REFERÊNCIAS BIBLIOGRÁFICAS}

1. Azevedo, L.A.S.; Juliatti, F.C.; Balardin, R.S.; Correa, O.S. Programa Syntinela: Monitoramento da Dispersão de Phakopsora pachyrhizi e alerta contra a ferrugem asiática da soja. Campinas: Emopi Gráfica e Editora. 2004. 24 p. (Boletim Técnico Syngenta Proteção de Plantas).

2 . Balardin,R.S.; Navarini, L.; Dallagnol, L.J.In: Epidemiologia da Ferrugem da Soja.In: Juliatti,C.F.;Polizel,C.A.;Hamawaki,T.O.1 ed.In: I Workshop Brasileiro sobre a Ferrugem Asiática: Coletânea.Uberlândia : EDUFU, p.39-50.2005.

3. Balardin, R.S. A ferrugem asiática da soja. Fitopatologia Brasileira, Brasília,v.29, supl., p.19,2004.(Resumo)

4. Barcelos, A.L.; Moraes-Fernandes, M.I.B.; \& Roelfs, A.P. Ferrugem da folha do trigo (Puccinia recondita) : durabilidade da resistência. Summa Phytopathologica, v.23, n.2,p.101-117,1997.

5. Bromfield, K.R.; Melching, J.S.; Kingsolver, C.H. Virulence and aggressiveness of Phakopsora pachyrhizi isolates causing soybean rust. Phytopathology, St.Paul ,v.70,n.1,p. 17-21,1980.

6. Bromfield, K. R., Hartwig, E.E. Resistance to soybean rust and mode of inheritance. Crop Science, New York,v.20,n.2,p.254255,1980 .

7. Brunelli, K.R., Silva, H.P., Camargo, L.E.A. Mapeamento de genes de resistência quantitativa a Puccinia polysora em milho. Fitopatologia Brasileira, Brasília, v.27, n.2. p.134-140, 2002.

8. Costamilan, L. M.; Godoy, C. V.; Yorinori, J.T. Avaliação de cultivares de soja com resistência à ferrugem asiática. Fitopatologia Brasileira, Brasília, v.28, supl., p.269, 2003. (Resumo)

9. Cruvinel, A.R.; Ottoni, G.; Lima, L.P.; Godoy, C.V. Utilização da área abaixo da curva de progresso da doença relativa para estudos epidemiológicos da ferrugem asiática da soja. In: 26 Reunião de Pesquisa de Soja da Região Central do Brasil, 2004, Ribeirão Preto. Anais. Londrina: Embrapa Soja, 2004. p.186.

10. Godoy, C.V.; Costamilan, L.M.; Canteri, M.G.; Almeida, A.M.R.; Piuga, F.F. Análise temporal do progresso da ferrugem da soja em Londrina (PR). Fitopatologia Brasileira, Brasília, v.28, supl., p.386, 2003. (Resumo)

11. Godoy, C.V; Arias, C.A.A. Resistência quebrada. Cultivar. Pelotas, v.5, n.55, p.28-29, 2003.

12. Hartman, G. L.; Wang, T. C.;Hymowitz,T. Sources of resistance to soybean rust in perennial Glycine species. Plant. Disease, St.Paul, v.76, n.4, 396-399,1992.

13. Hartman, G.L. Highlights of soybean rust research at the Asian Vegetable Research and Development Center. In: Soybean Rust Workshop, 1995.Urbana,Illinois: College of Agriculture, Consumer, and Enviromental Sciences, National Soybean Research Laboratory, 1995.p.19-28..

14. Juliatti, F.C.; Borges, E.N.; Passos,R.R.; Caldeira Júnior, J.C.; Juliatti,F.C.; Brandão, A M. Doenças da soja. Cultivar, Pelotas,n.47, 13p.,2003.

15. Juliatti, F.C.; Polizel, A. C.; Juliatti, F.C.. Manejo integrado de doenças da soja. Uberlândia : Composer Gráfica e Editora, 2004.327 p.

16. Marchetti, M.A. ;Uecker, F.A.; Bromfield, K.R. Uredial development of Phakopsora pachyrhyzi in soybeans. Phytopathology,St.Paul, v. 65,n.4.822-823, 1975.

17. Parlevliet, J.E. Components of resistance that reduce the rate epidemic development. Annual Review Phytopathology, St.Paul,v.17,n.2,p.203-222,1979.

18.Parlevliet, J.E. Strategies for the utilization of partial resistance for the control of cereal rusts. In: SIMMONDS, N.W., RAJARAM, S. Breeding strategies for resistance to the rust wheat. Mexico, CIMMYT, 1988.p.48-62.

19.Prabhu, A.S., Guimarães, E.P., Filippi, M.C., Araújo, L.G.; Cutrim, V.A. Expression of resistance in rice hybrids to Pyricularia grisea. Fitopatologia Brasileira, Brasília, v.27,n.5, p.454-459,2002.

20.Shaner, G.E.; Hess, F.D. Equations for integrating components of slow leaf rusting resistance in wheat.Phytopathology, St.Paul, v. 18, n.4, p.471-475.1978.

21.Wang,T.C.; Hartman, G.L. Epidemiology of soybean rust and bre- 
eding for host resistance. Plant Protection Bulletin,Greensboro, v.34, n.1,109-124.1992

22.Vale, F.X.R., Zambolim, L.; Chaves, G.M. Efeito do binômio temperatura-duração do molhamento foliar sobre a infecção por Phakopsora pachyrhizi em soja. Fitopatologia Brasileira, Brasília v.15, p.2000-2002. 1990.

23.Yorinori, J.T.; Godoy, C.V.; Paiva, W.M.; Frederick, R.D.; Cos- tamilan, L.N.; Bertagnolli P.F.; Nunes JR., J. Evolução da ferrugem da soja (Phakopsora pachyrhizi) no Brasil, de 2001 a 2003. In: Congresso Brasileiro de Fitopatologia, ,2003. 36.,Suplemento.... Uberlândia: S210, 2003.

24. YORINORI, J.T. Soybean rust: general overview. In: World Soybean Research Conference, 2004,Foz do Iguaçu,. Proceedings. Londrina: Embrapa Soja, 2004.p. 1299-1307 p. 